\title{
On the dynamic response of hardening systems
}

\author{
O. Sircovich Saar \\ Principal of Sircovich Saar Engineering, Israel
}

\begin{abstract}
This paper relates to hardening systems, their response to dynamic forces and their contribution to seismic isolation of buildings' foundations.

The free vibration curve for a structure of continuous gradual changing of period and frequency, the dynamic load factor (DLF) for a suddenly applied constant load, and the curve of resonance for a pulsating sinusoidal force, are analyzed from the perspective of a structural engineer, which is essentially different from that of a researcher.

The paper suggests a new approach for base seismic isolation, which is a combination of a base isolation device and a hardening steel structure.

While the contribution of the isolation device is its characteristically high flexibility, the contribution of the steel structure consists of a smooth reduction of the building's base displacement under a given earthquake.

The combined isolation system also provides a gradual limitation of the building's base displacement under an unexpected increase of the earthquake's peak ground acceleration (PGA).

Keywords: seismic isolation device, hardening steel structure, smooth reduction of base displacement, limitation of base displacement.
\end{abstract}

\section{Introduction}

This paper presents a new approach for base seismic isolation, which is a combination of a base isolation device and a hardening steel structure.

According to the results of preliminary investigations, this combination is conducive to a remarkable reduction of the maximum displacement of the isolated structure and to an appreciable limitation of this displacement under and unexpected increase of the design earthquake's PGA.

The response of a linear elastic structure, (curve 1 in fig. 1), subjected to a dynamic load is very well known and its basic characteristics, such as natural 
circular frequency and period, resonance and the effect of damping, lie at the basis of the dynamic analysis of structures.

The majority of structures designed by structural engineers all over are ductile structures, (curve 2 in fig. 1). Though there is no a straight forward solution for their equation of dynamic equilibrium of forces, as is the case with linear elastic structures, their dynamic response has been for decades now the object of vast and thorough study.

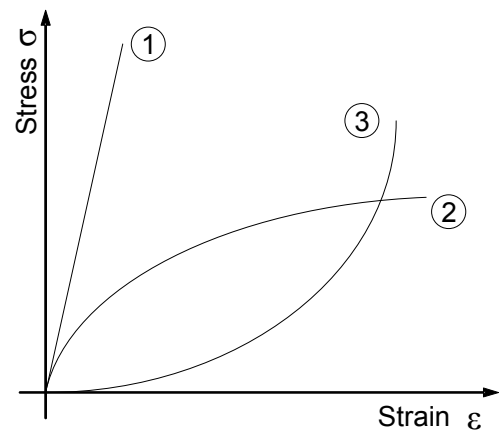

Figure 1: 1) Linear elastic structure. 2) Ductile structure. 3) Hardening structure.

Hardening structures (curve 3 in fig. 1) are not common in the work of structural engineers, Sircovich Saar [1]. The knowledge about their dynamic response comes mainly from studies of physics, such as for example the diagram of resonance in fig. 2 .

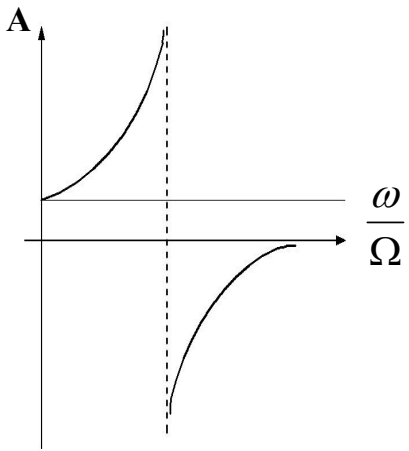

Figure 2: Frequency-amplitude response curve for a hardening structure; a "jump and drop" function.

\section{Hardening structures}

For the purpose of introducing an additional steel structure to a base isolation system, understanding the subject of period $\mathbf{T}$ of a hardening structure seems an 
adequate starting point even though the concept of period may appear somehow evasive at first.

Fig. 3a shows a schematic representation of the horizontal motion of mass $\mathbf{M}$ and fig. $3 \mathrm{~b}$ shows the curve of variation of the spring's force.

a)

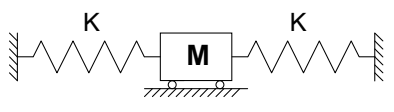

b)

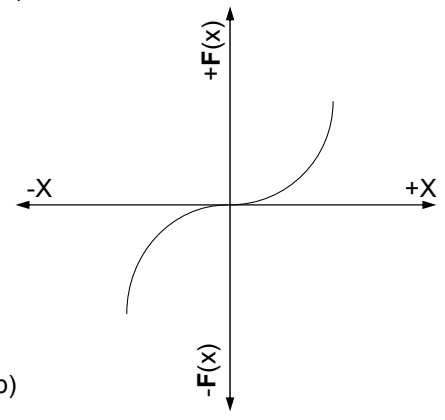

Figure 3: Hardening spring-mass system.

The known equation of equilibrium of forces in the un-damped free vibration is:

$$
\mathbf{F}_{\mathrm{I}}+\mathbf{F}_{(\mathrm{X})}=0
$$

We choose the family of functions $\mathbf{F}(\mathrm{X})=\mathbf{K} \cdot \mathrm{x}^{\mathrm{m}}$ for our study, and in particular

$$
\mathbf{F}_{(\mathrm{X})}=\mathbf{K} \cdot \mathrm{x}^{3}
$$

The equation of equilibrium of dynamic forces for the free vibration becomes

$$
\mathbf{M} \cdot \ddot{\mathbf{x}}+\mathbf{K} \cdot \mathbf{x}^{3}=0
$$

a nonlinear differential equation of the second order and third rank. Since it is no possible to solve this equation with analytical formulation, the common practice is to make use of a numerical procedure.

The mathematical treatment of a nonlinear design situation is usually a stepby-step procedure, with differential increments. In each of those steps the dynamic system can be considered linearly elastic. Each step starts with the structural and load characteristic from the end of the preceding incremental step. The mathematical procedure is by integration of differential equations of dynamic forces into a sequence of linear structures with new properties at the beginning of each step. There are many procedures available for performing the step-by-step integration, such as the very well known Newmark's $\alpha-\delta$ method.

For the structural engineer those mathematical ways are like working with a black box that does not contribute much to he's or her physical understanding of the response. Conversely, the approach proposed here, from the perspective of a 
structural engineer, is essentially different from that of a researcher. Though it may be slightly less accurate, it suffices to provide a clear picture of the results.

The continuous force-deformation curve, $\mathbf{F}(\mathrm{x})$ of fig. $3 \mathrm{~b}$, is considered as composed of a sequence of dots " $n$ ", as in fig. $4 a$, and is replaced by a sequence of tangential straight lines according to a sequence of $\Delta \mathrm{x}$ steps, as in figs. $4 \mathrm{~b}$, $4 \mathrm{c}$.

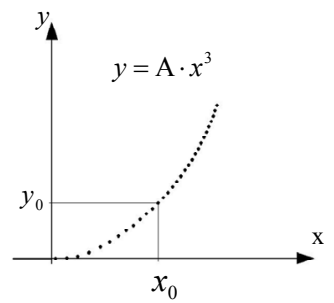

a)

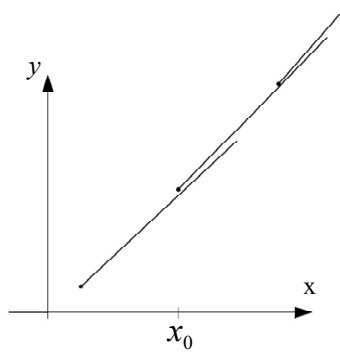

b)

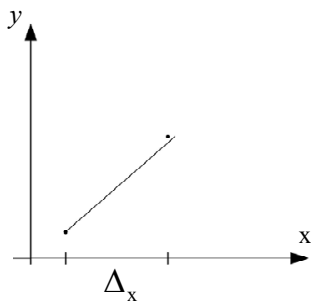

c)

Figure 4: a) The cubic springs represented by a sequence of dots. b) An enlargement of only three consecutive dots. c) Only one $\Delta x$ increment along one of those tangents.

a)
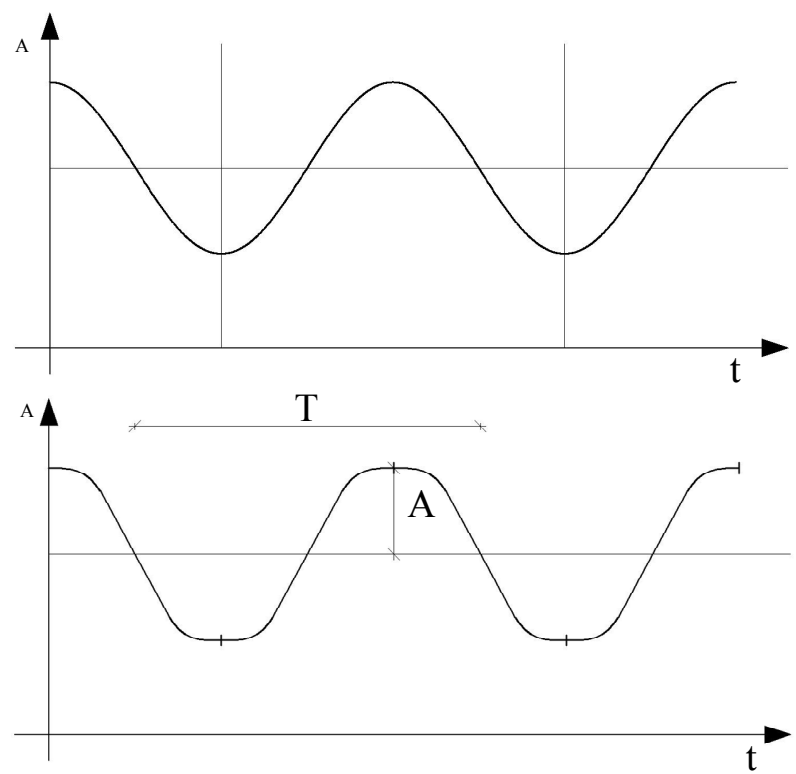

Figure 5: a) Harmonic free vibration of a linear system. b) Periodic free vibration of a cubic spring. 
The equation of equilibrium of forces in motion can be replaced, for any dot "n", by

$$
\mathbf{M} \cdot \ddot{\mathbf{x}}+\left(\mathbf{K} \cdot \mathbf{x}_{\mathrm{n}}^{2}\right) \cdot \mathbf{x}=0
$$

Since $\mathbf{K} \cdot \mathbf{X}_{\mathrm{n}}^{2}$ can get a numerical value for any dot "n", this equation has an analytical solution and the response curve for the cubic spring system becomes a sequence of dots, according to a sequence of equal $\Delta t$ intervals of time, which depicts the nature of the response; see fig. 5.

The relation between the amplitude " $\mathbf{A}$ " of a free motion and its period " $\mathbf{T}$ " appears to be a very simple one:

$$
\text { A.T }=\text { Const' }^{\prime}
$$

which means the bigger the amplitude of the free motion the shorter its period.

For one quarter of the free vibration cycle the curve of figure $5 \mathrm{~b}$, is given by the following expression as a succession of harmonic motions:

$$
\left.x\right|_{1} ^{+n}=c_{11} \sin \omega_{1} \Delta t+c_{12} \cos \omega_{1} \Delta t ; c_{21} \sin \omega_{2} \Delta t+c_{22} \cos \omega_{2} \Delta t ; \ldots c_{n 1} \sin \omega_{n} \Delta t+c_{n 2} \cos \omega_{n} \Delta t
$$

In Fig.6 is represented the DLF diagram for a suddenly applied constant load $\mathbf{P}$ in the same hardening curve of our study. It was worked out by mathematical regression on particular values applying the same general approach.

\section{$\triangle \mathrm{DMF}$}

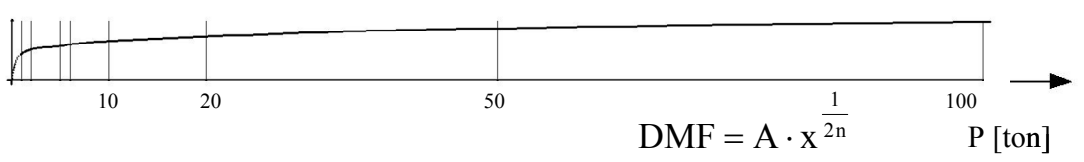

Figure 6: DLF curve for a suddenly applied load.

\section{The isolation device - steel structure combination}

The idea of seismic isolation is rather simple: reduction of the earthquakeinduced inertial loads by shifting the fundamental frequency of the structure out of the dangerous-for-resonance range, Komodromos [2], and concentration of deformation and energy dissipation demands at the isolation system; seismic isolation reduces the inter-storey displacements and floor accelerations of the structure under strong seismic motion. The superstructure remains essentially undeformed, moving like a rigid body, which prevents damage to its structural and non-structural components; see fig. 7.

This paper suggests a new approach for base seismic isolation, which is a combination of a base isolation device and a hardening steel structure. The basic idea is to incorporate a particular steel structure in the same inter-space level allocated for the isolation device. 
Once the relation between amplitude of motion $\mathbf{A}$ and period $\mathbf{T}$ of the hardening structure becomes clear, combining it with a base isolation device comes naturally. While the contribution of the isolation device is its characteristically high flexibility, the contribution of the steel structure is a smooth reduction of buildings' base displacement under a given earthquake; see results in fig.10a versus fig. 9a and fig. $10 \mathrm{~b}$ versus fig. 9b. The hardening steel structure's contribution lies in its continuous changing of period $\mathbf{T}$ with the continuous changing of amplitude of base displacement (see hardening curve on fig.8b), minimizing in this manner danger of resonance between the instantaneous SDOF's frequency and some harmonic components of the ground motion.

In the practical implementation of seismic isolation a main imposition to the architectural/structural design is the wide gap required by calculations between the building's superstructure and a surrounding wall at the isolation level. Based on energy dissipation considerations the dimension of this gap should be kept reduced as much as possible, Dolce et al. [3]. The combined isolation system provides also a limitation of buildings' base displacement under an unexpected increase of the earthquake's peak ground acceleration (PGA); see results in fig. $11 \mathrm{a}$ versus fig. $10 \mathrm{a}$ and fig. $11 \mathrm{~b}$ versus fig. $10 \mathrm{~b}$.

a)

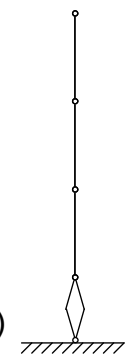

b)

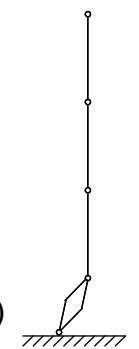

Figure 7: $\quad$ Fundamental mode of a seismic isolated multi-storey building.
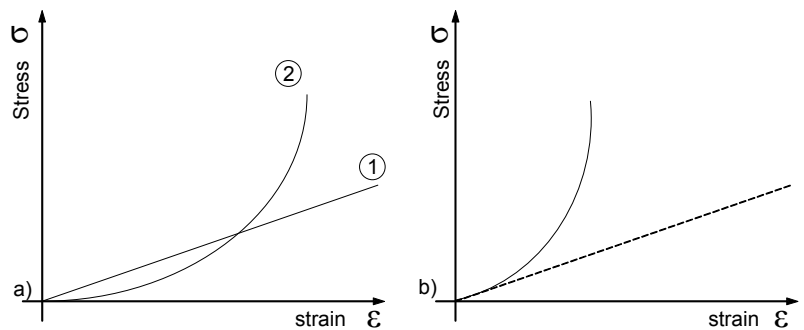

Figure 8: a) Base isolation device curve (1). Hardening structure curve (2). b) Isolation device hardening structure's combined curve. 


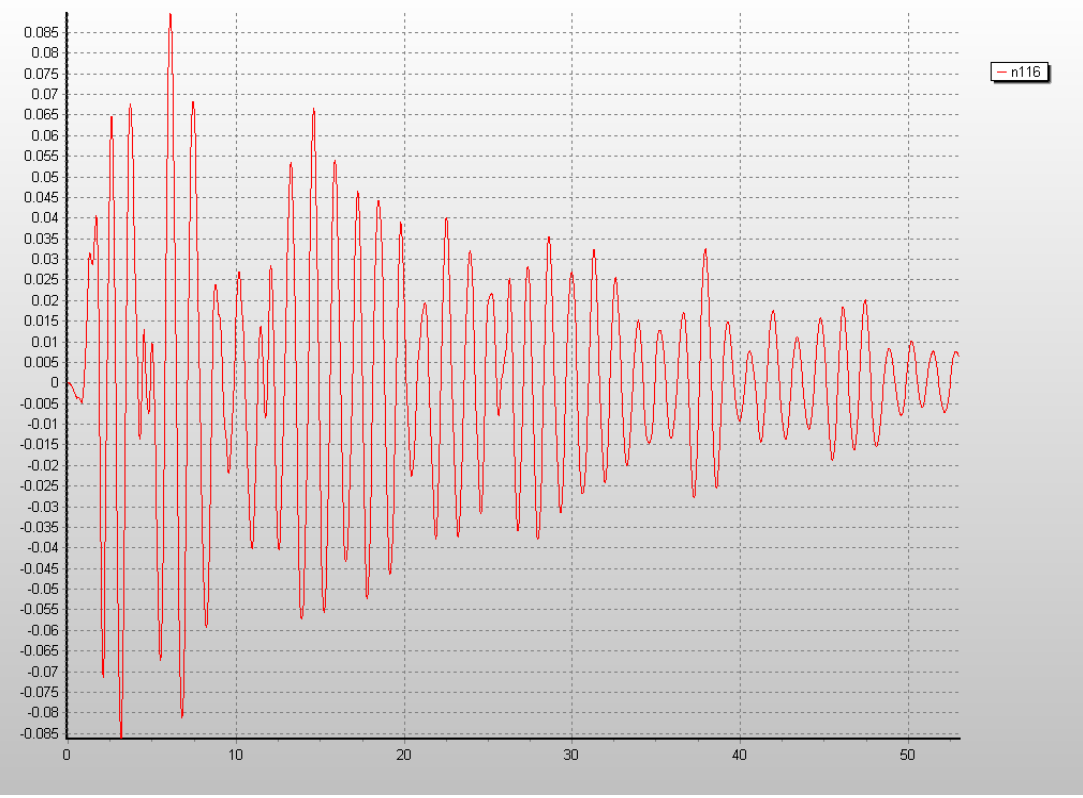

a)

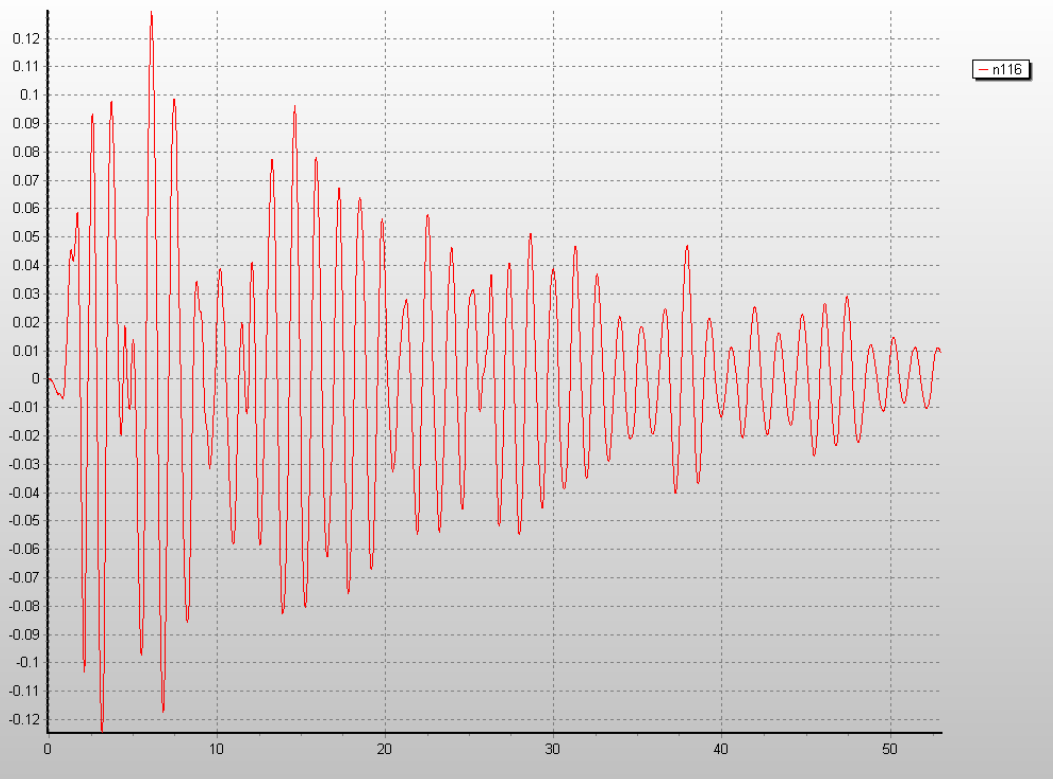

b)

Figure 9: Displacement-time response diagram for El Centro excitation. a) Linear elastic structure. b) Elastoplastic structure. 


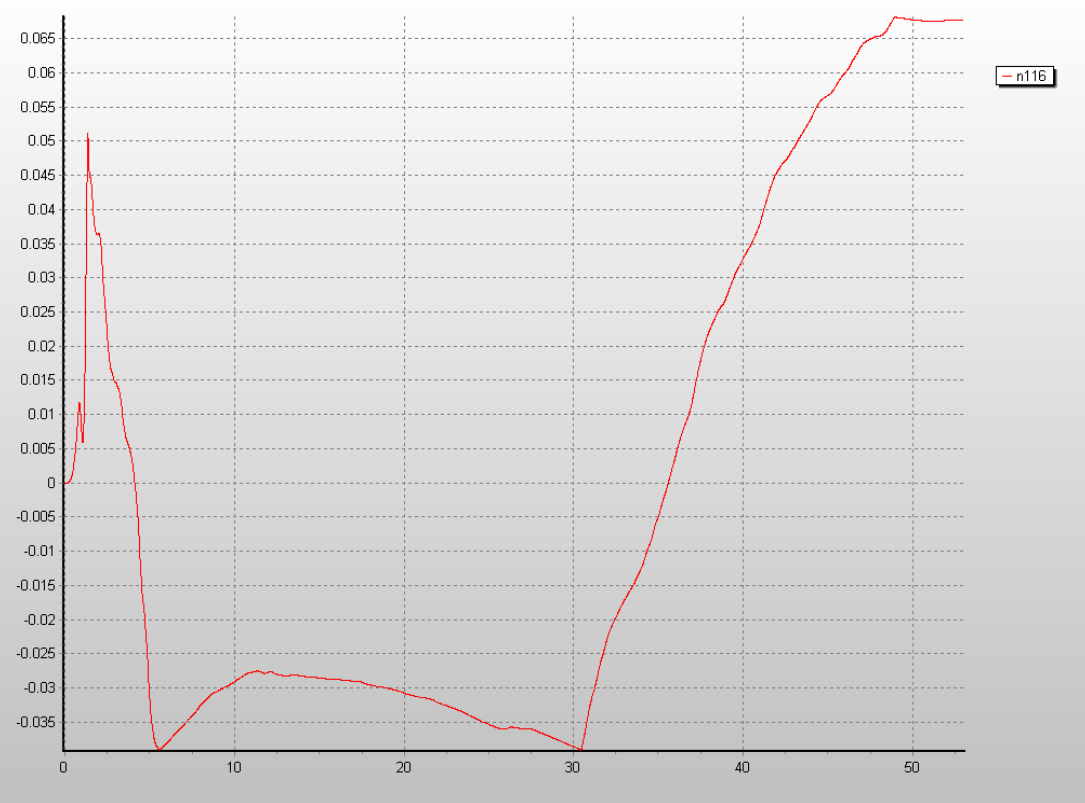

a)

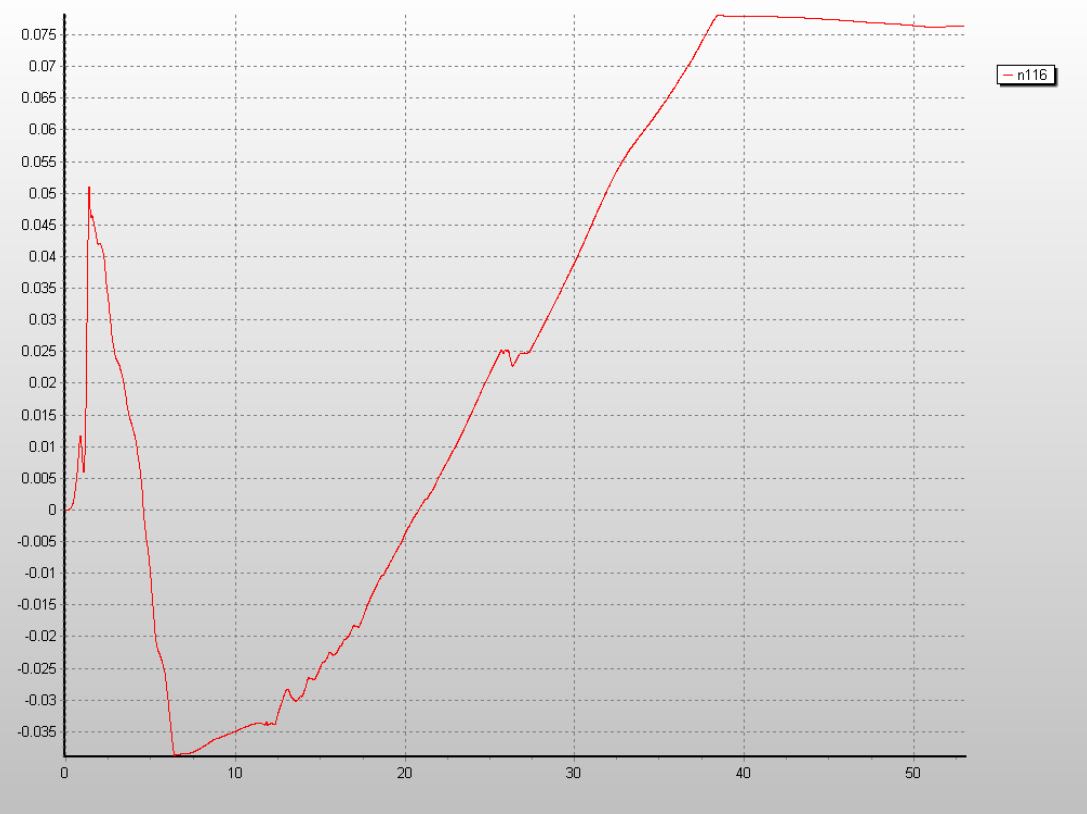

b)

Figure 10: Displacement-time response diagram for El Centro excitation. a) Hardening elastic structure. b) Hardening elastoplastic structure. 


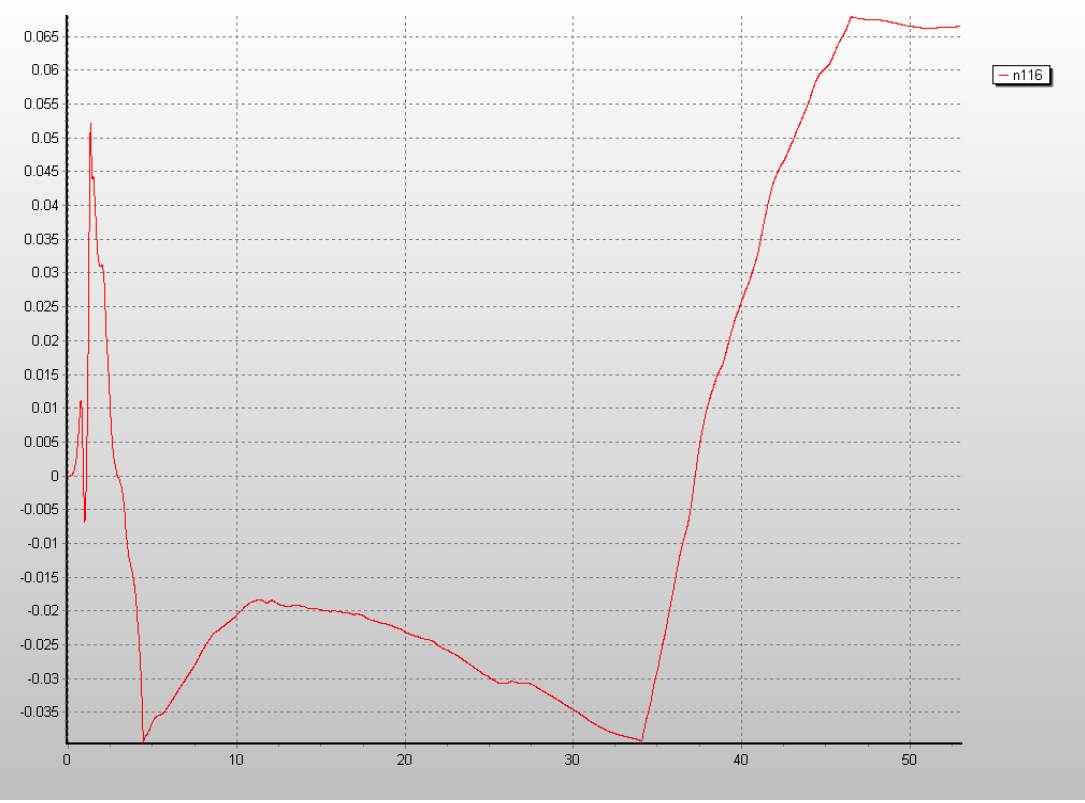

a)

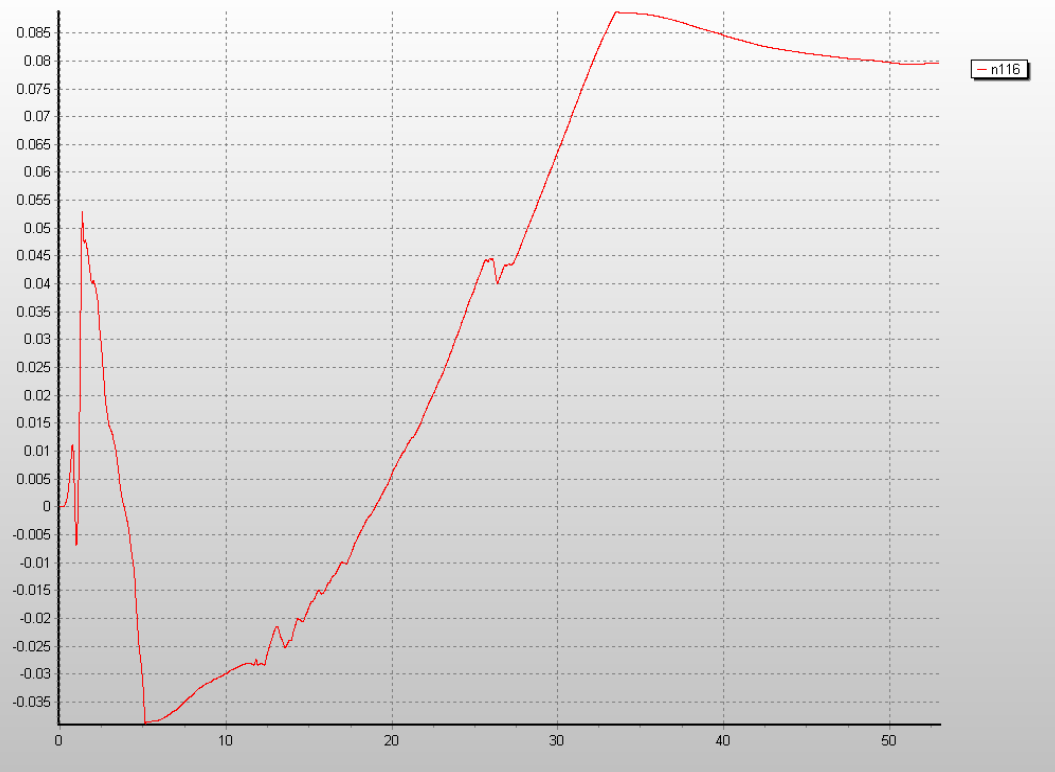

b)

Figure 11: Displacement-time response diagram for El Centro excitation factorized to $150 \%$ PGA. a) Hardening elastic structure. b) Hardening elastoplastic structure. 


\section{Displacement-time response diagrams}

Two different SDOF structures were subjected to the input of ground motions from several recorded earthquake's ground acceleration-time histories: one erected on a seismic isolation device and a second erected on the seismic isolation combination. The structures, both with elastic and elastoplastic response, see fig. 12, were checked for various periods $\mathbf{T}$ from $1 \mathrm{sec}$. to $4 \mathrm{sec}$; the linear stiffness of the selected base isolation device, of the elastomeric bearing type, was $26 \mathrm{t} / \mathrm{m}$ and the stiffness of the isolation combination was calculated according to the following formula:

$$
\mathbf{F}(\mathrm{x})=26 \cdot \mathrm{x}+\mathbf{A} \cdot(\mathrm{x}-\mathbf{B})^{3}
$$

for different values for " $\mathbf{A}, \mathbf{B}$ “, and for " (x - B) $\geq 0$ “.

Comparison of their response reveals the following results, see figs. 9-11:

1) reduction to approximate $70 \%$ of the maximum base displacement;

2) no significant increment of base displacement for an increment to $150 \%$ on peak ground acceleration, (150\% PGA).

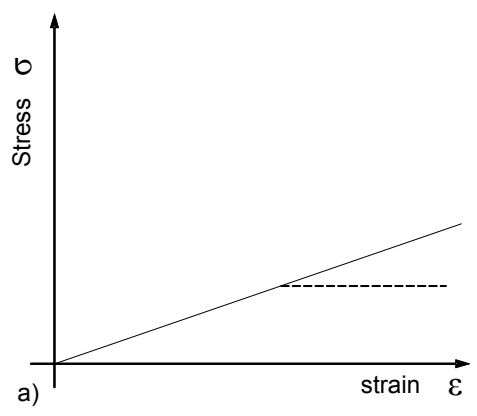

Figure 12: a) Elastic structure. b) Hardening structure.

\section{Concluding comments}

This paper presents a new approach to building base seismic isolation, which is a combination of a base isolator device with a steel hardening structure. It is an original idea that still requires investigation before we can reach comprehensive conclusions.

Several comments, though, can be made already.

1) Addition of a hardening structure to a seismic elastomeric bearing isolation system significantly reduces the superstructure's maximum base displacement.

2) The possibility that the combined system provides a limit to "maximum overall base displacement" is indicated as probable. This preliminary finding should be further checked on a selection of acceleration-time histories input. 
For a proper evaluation of the isolation combined system the SDOF structure should be replaced by an MDOF structure, with due consideration of damping. The investigation of base displacement should be complemented with floor accelerations, inter-storey drifts and shear forces.

\section{References}

[1] O. Sircovich Saar, A new type of Hardening Structure, Proc. of the International Conference on Mobile and Rapidly Assembled Structures, eds. F. Escrig, C. A. Brebbia, WIT Press, Madrid, pp. 113-124, 2000.

[2] P. Komodromos, Seismic Isolation for Earthquake-Resistant Structures Southampton, U.K., WIT Press, 2000.

[3] M. Dolce, A. Martelli, G .Panza, Moderni metodi di protezione dagli effeti del terremoto, Milan, Italy, 21 mo SECOLO s.r.1., pp. 137, 2006. 